\title{
Physics Entrance Testing at Technical University
}

\author{
Svetlana L. Timchenko ${ }^{1 *}$, Mikhail L. Pozdushev ${ }^{1}$, and Nikolai A. Zadorozhnyi ${ }^{1}$ \\ ${ }^{1}$ Bauman Moscow State Technical University, 2nd Baumanskaya str., 5/1, 105005, Moscow, Russia
}

\begin{abstract}
The paper deals with the organization of entrance physics testing for first-year BMSTU students of all majors and specialties. The role and position of testing in the educational process of a technical university is discussed on the example of entrance testing conducted by the Department of Physics. The advantages of entrance testing as one of the types of control of students residual knowledge are shown. The subjects of the tasks of entrance testing are presented and an example of typical variants of test tickets is given. The analysis of the degree of solution of the input testing problems for all faculties has been carried out. It has been established that the following sections of the school physics course: "Electrostatics", "Magnetism", and "Mechanical vibrations" cause the greatest difficulties. A comparative analysis of the entrance test has been conducted at the faculties of "Basic Sciences" and "Special Engineering" for the 2018 and 2019 academic years. The connection between the entrance testing results and passing scores at the faculties of technical university ihas been revealed. It has been shown that entrance testing allows to determine the percentage of students' retained knowledge at the school physics course and make adjustments to organize students' additional auditorial and individual work. The lecturer has the opportunity to correct the presentation of the physics course in order to increase the percentage of retained knowledge in future.
\end{abstract}

\section{Introduction}

At the present stage of the education development in Russia, the Russian higher school is in the direction of serious reforms, the purpose of which is to create a training system for the engineering corps that ensures the implementation of the strategy for innovative development of the Russian Federation economy. In view of these reforms, the experience gained by the Bauman Moscow State Technical University, which is the pioneer in the introduction of practice-oriented methods for training specialists in engineering areas [1,2], becomes of key importance. The unique combination of practical training with fundamental theoretical education turned out to be extremely effective and allowed us to form a cohort of prominent academics of world engineering science. Nowadays, the educational process, implemented at a technical university, allows students to acquire knowledge and practical skills in modern engineering.

\footnotetext{
* Corresponding author: timch@bmstu.ru
} 
The great attention is given to the quality of education, especially in such disciplines as physics and mathematics, in all developed countries. The level of development of science, the economy and the country welfare largely depends on the quality of teaching these disciplines. That is why, in foreign literature, a lot of attention is paid to the problem of the quality of knowledge, especially in mathematics and physics [3-6]. The authors of educational programs believe that teachers need to convince students that mathematics and physics are not "random" facts and formulas, but an interconnected network of concepts [7], to improve the quality of knowledge. Therefore, it is necessary to study physics as a holistic knowledge system for building a holistic picture of the physics discipline for students and for creation of links between its topics. Moreover, testing is often used to verify the education quality. In this regard, students testing at all stages of education at a technical university is practically useful.

An increase in the number of courses taught at the departments of a technical university requires monitoring the knowledge assimilation acquired by students during the learning process. Control of basic knowledge in physics is often carried out through testing. Testing, as a control form of not only basic, but also students' current knowledge, allows lecturers to receive more accurate and objective information about the level of students' knowledge acquisition, as well as to reveal retained knowledge. In higher education, testing is positioned and used as one of the operational forms of monitoring the quality of students' education, which allows to estimate objectively the amount of learned discipline. The use of tests on various topics with varying degrees of difficulty makes it possible to identify if the students' achievements meet the demands of the state educational standard requirements [810]. At the same time, the testing conditions and contents should be equal for all students. In general, testing allows to organize three important functions of the educational process at the university: diagnostic, learning and educational.

Testing is not only an indicator of the education quality, a means of determining student achievements, but also an indicator of the effectiveness of the university educational system methodological component. Nowadays the educational process organization includes learning and the usage of modern computer technologies [11,12]. This allows to realize the individualization and differentiation of education. Various forms of testing are used to diagnose the degree of educational material development. It is important for the selected form to allow obtaining objective results of testing skills quickly [10-13].

Computer testing is the most effective way to carry out the testing process and allows to control students' knowledge level operationally. As practice shows, the use of computer testing provides a unity of testing requirements, the content of test items and the discipline digestion within an institution. At the same time, the system of knowledge testing at a university is not perfect, since it cannot teach a student to express his thoughts, make up a chain of logical reasoning that allows solving a non-standard practical problem. Testing contains randomness. For example, students can choose the right answer without deeply understanding the physical content of the task quite often. A dialogue between teacher and student is necessary in order to develop a true understanding of a physical problem and its solution. Test tasks should contain not only questions and tasks with a choice of answers, but also tasks that require the creation of a physical model and its solution.

The requirements for continuous improvement of the education quality lead to dynamic improvement of teaching methods and technologies. For example, a new technology, including information and computer technologies introduction in the process of "Informatics and Computing" course, was developed. It included cycles of lecturesvisualizations, which allowed to effectively improve the development of disciplines in this education area [11].

Subject entrance testing and further analysis of its statistical data make it possible to accompany educational process monitoring and control as part of the pedagogical 
management of educational services, as well as to design the didactic content for the mathematical and physical educational disciplines of educational programs in accordance with the objectives to ensure the education quality [11-14]. Also the purpose of diagnostic testing is to develop their own general-professional (OGPC-1, 2, 4, 7) and professional competencies (OPC-3) for students of undergraduate and specialist programs $[1,2,8]$, through the use of digital learning or distance learning technologies $[15,16]$.

\subsection{Modular-rating system}

The path of the educational process in a general physics course at a technical university contains not only lecture courses, seminars, laboratory works, but also intermediate testing. Since 2016 a modular rating system (MRS) has been introduced in the educational process at BMSTU. The rating system is an assessment system of a funded type that reflects student's performance, their creative potential, psychological and pedagogical characteristics; integrated assessment of all types of student's activities; a quantitative characteristic of the educational work quality, expressed in points and aimed at stimulating the rhythmic, interested, active work of the student; a numerical value expressed in points and integrally characterizing the student's performance in one or several subjects during a certain period of study (module, half year, year, etc.). The purpose of a rating system in the educational process is to create conditions for individualizing the learning process, activating the educational and cognitive activities of students, motivating their independence by means of timely and systematic evaluation of the results of their work in accordance with the student's real achievements.

The Regulation on the module-rating system for the discipline "Physics" was developed on the basis of the "Regulation on the current monitoring of the performance and intermediate performance review of BMSTU students". The module-rating system is based on the principle of dividing the discipline into the modules and forming the student rating based on the exam results. The resulting assessment of the student's knowledge of the discipline is based on a generalization (integration) of the assessments of the individual stages of the student's work: the results of the various forms of current and intermediate control. All forms of current and intermediate control are evaluated on the basis of a 100point total scale. The marks which are below the minimum boundary, earned in each module, are equal to mark "unsatisfactory".

The material is divided into two modules at each semester. Control of the first module with an entry of relevant information into the «Electronic University» system is planned at 10 th week of the semester, control of the second module - at 16th week. The maximum number of points a student can get by completing the educational activities provided in the schedule (including an exam or an end-of-term test) in accordance with the terms indicated in the plan is 100 points. At the beginning of the 11th and 17th weeks, information on the results of the implementation of educational activities is mandatory transferred to the electronic university database, which automatically determines the student's rating at the specified time of study in the semester.

A necessary criterion for a performance review of a student in module is to receive points for each module review position not lower than the minimum admissible. Review positions include attending lectures, attending and working at seminars, performing a semester homework and it's presentation, performing laboratory works and their presentation, and passed midterm controls.

A student can get additional review points if he performs academic work not only provided by the calendar curriculum, for example: he successfully takes part in physical olympiads and student scientific conferences (by presenting a report), is engaged in scientific work at the Department of Physics and etc. The amount of additional points in 
each particular case is determined by the head of the department (no more than 10 points per module, or 20 points per semester) according to the presentation of the lecturer. The amount of additional points that students can get, for example, for participating in olympiads and other events, is determined by the head of the department.

The student receives a positive mark in discipline for the semester if he has a positive mark for each module and a positive mark for the final control during the exam.

The following criteria can be distinguished as the advantages of a modular-rating system:

- learning objectives correlate with the learning outcomes of each student;

- educational information is presented in blocks;

- students' educational and scientific activities increase;

- the motivation for the discipline study increases;

- an motivation for systematic work throughout the semester increases;

- the level of mastering the discipline and the quality of student's learning are increasing.

\section{Diagnostic testing of first-year students}

Let's consider the testing system as a form of knowledge control. We'll define the role and place of testing in modern education using the example of the Department of Physics at a technical university.

Analysis of BMSTU students exam results at the course of general physics points to the absence of a direct correlation between the examination marks (Unified State Examination) scored by applicants and the marks already received by students during the semester. In order to determine the educational level of students in the subject "Physics", at the BMSTU Department of Physics, the entrance testing has been undergoing since 2010. Entrance testing in physics is carried out in the second semester of the first year for students of all majors, for both bachelors and specialists. Testing takes place during the first two education weeks of the spring semester. This type of control allows to identify the level of the retained knowledge in physics at the secondary school level by the beginning of its study at a technical university. Considering that a little more than six months have passed from the Unified State Examination to the timewhen students started to study at the Department of Physics, it should be expected that the knowledge gained by first-year students in school during the educational process and the process of preparing for the Unified State Examination is not completely lost.

Diagnostic testing of first-year students is carried out during the first laboratory lesson in physics for 50 minutes. Testing is conducted by teachers leading laboratory classes. Students are offered tasks of the examination level. The content of the examination work corresponds to the federal state educational standard of higher professional education and the BMSTU curriculum.

Each student has an individual work consisting of 10 tasks. Entrance testing controls students' knowledge and skills in the following sections of the general physics course for students:

- mechanics (kinematics, dynamics of a material point, conservation laws in mechanics, dynamics of a rigid body);

- statics and hydrostatics;

- the basics of molecular kinetic theory and thermodynamics;

- electrostatics;

- electricity;

- a magnetic field; 
- mechanical vibrations and waves.

The total number of tasks in the examination work in each section is approximately proportional to its substantial content and the study time allocated for this section in a physics course at school. Student's marks for each task were based on a ten-point system. It is important that the solution for tasks has to be a result of the written independent work of students, and not the choice of the correct answer. An example of the physics entry test tickets are given below.

\subsection{The examples of the tickets}

\section{Variant 1}

1. The braking distance of the car is $1,5 \mathrm{~m}$ at a speed of $15 \mathrm{~km} / \mathrm{h}$. What will be the braking distance at a speed of $90 \mathrm{~km} / \mathrm{h}$ if the braking in both cases occurs with the same acceleration?

2. A body (mass $=2 \mathrm{~kg}$ ) moves on a horizontal surface with $2 \mathrm{~m} / \mathrm{s}^{2}$ acceleration under the action of a horizontally directed force. Find the magnitude of this force if the friction coefficient between the body and the surface is $0,2 \mathrm{~m} / \mathrm{s}, g=10 \mathrm{~m} / \mathrm{s}^{2}$.

3. A person with mass $M=60 \mathrm{~kg}$ is located on a resting cart, which mass is $m=20$ $\mathrm{kg}$. A person begins to move along the cart with a speed of $v=1 \mathrm{~m} / \mathrm{s}$ relative to the cart. What is the speed of the cart $u$ relative to the Earth?

4. Find the work $A$ that is needed to be done to compress the spring by $20 \mathrm{~cm}$, if the spring is compressed by $1 \mathrm{~cm}$ under the action of a force of $30 \mathrm{~N}$.

5. What force must be applied to keep a stone in the water, if the weight of the stone in the air is $350 \mathrm{~N}$ ? The density of the stone substance is $2500 \mathrm{~kg} / \mathrm{m}^{3}$.

6. How will the average quadratic velocity of gas molecules change if the temperature rises by 2 times?

7. The same positive charges $q$ are located at the three vertices of the square, with side a. Find the electric field strength $E$ at the fourth peak.

8. In how many equal parts do you need to cut the conductor with resistance $\mathrm{R}=25$ Om in order to get resistance $\mathrm{r}=1 \mathrm{Om}$ when these parts are connected in parallel?

9. A conductor of length $/$ moves with constant speed $v$. Determine the voltage at the ends of the conductor in a uniform magnetic field with induction $B$. The conductor is perpendicular to the magnetic-field lines and the speed of the conductor is perpendicular to the conductor and vector $\vec{B}$.

10. What is the length of a mathematical pendulum oscillating at the same frequency as a load of $0.2 \mathrm{~kg}$ mass suspended on a spring with a stiffness of $2 \mathrm{~N} / \mathrm{m}$ ?

\section{Variant 2}

1. The point moves along the $O x$ axis according to the law $x(t)=5+3 t-9 t^{2}$. All values are given in SI. At what distance from the origin the speed of the point will be zero?

2. An astronaut (mass $=80 \mathrm{~kg}$ ) presses on a seat with a force of $4500 \mathrm{~N}$ during the vertical rocket takeoff. Find the rocket acceleration assuming that $g=10 \mathrm{~m} / \mathrm{s}^{2}$.

3. A bullet of mass $m$ flying horizontally with the speed $v_{0}$ hits a block lying on a smooth floor, and goes through it. The mass of the block is equal to $M$, the speed of the bullet after the shot is $v$. Determine the speed of the block. 
4. The ball is thrown vertically upwards with a speed of $v_{0}=10 \mathrm{~m} / \mathrm{s}$. At what height does the kinetic energy of the ball decrease by 2 times?

5. A homogeneous body floats on the surface of kerosene so that the volume of the submerged part is 0.92 of the total volume $V$ of the body. Determine the volume of the submerged part $V_{\text {погруж }}$ when the body is located on the water surface. Kerosene density is $\rho_{\mathrm{K}}=0,8 \cdot 10^{3} \mathrm{~kg} / \mathrm{m}^{3}$, water density is $\rho_{\mathrm{B}}=10^{3} \mathrm{~kg} / \mathrm{m}^{3}$.

6. Argon is located in a 2-liter flask at a normal atmospheric pressure of $100 \mathrm{kPa}$ and a temperature of $300 \mathrm{~K}$. How much the flask mass with gas will decrease if the gas is evacuated from it. The answer should be expressed in grams and rounded to the nearest tenth. The argon molar mass is $0.04 \mathrm{~kg} / \mathrm{mol}$.

7. The equal positive charges $q$ are located at the three points of the square with the side a. Find the potential in the fourth point.

8. Two resistors with resistances $R_{1}$ and $R_{2}$ are connected alternately to a current source. Moreover, they consume the equal power. Find the source resistance.

9. A proton and an electron accelerated by the equal potential difference fly into a uniform magnetic field. How many times is the curvature radius of the $\mathrm{R}_{1}$ proton trajectory greater than the curvature radius of the $\mathrm{R}_{2}$ electron trajectory? Masses of particles are known.

10. The total energy of the body performing harmonic vibrations under the action of elastic force is $\mathrm{W}=3 \cdot 10^{-5} \mathrm{~J}$, and the maximum force acting on the body is $\mathrm{F}=1,5 \cdot 10^{-3} \mathrm{~N}$. Find the amplitude of the body's vibrations.

The maximum mark for the work is 100 . The equivalence of the examination work variants is ensured by the same average complexity of the variants, as well as by the similar distribution of tasks in each variant by type of activity and thematic content. The tasks of a basic level of difficulty are estimated in 8 points. The tasks of a high level of difficulty are estimated in 10-12 points.

\section{The results of the entrance testing}

The graphs and diagrams below show the distribution of the average score depending on the task number and, therefore, it's subject, as well as passing grades for 2017, 2018, 2019 years.

Eleven faculties of the university where the course of general physics is held: "Mechanical Engineering" (SM), "Robotics and Complex Automation" (RK), "Radioelectronics and Laser Technologies" (RL), and "Biomedical Technologies" (BMT), "Power Engineering" (E), "Materials and Technologies" (MT),"Fundamental Sciences" (FN), "Engineering Business and Management" (IBM), "Informatics and Control Systems" (IU), "Rocket and Space Technology" (RKT) and "Radio Engineering" (RT) have been selected for the analysis of the tasks solvability. Figure 1 shows the average score for all control tasks received by students in all faculties for 2018 and 2019 years.

Fig. 2 shows the distribution of the average score for each task, depending on the faculty. 


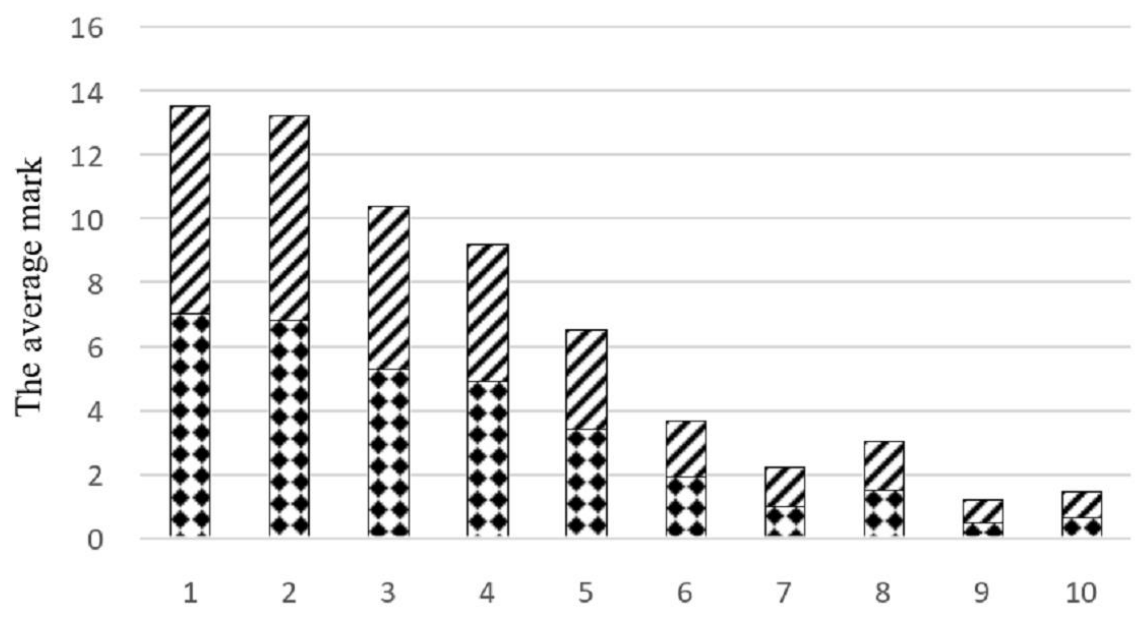

Task number

2019 year $\square 2018$ year

Fig. 1. The average mark for the tasks solved in all BMSTU faculties in 2018 and 2019 years.

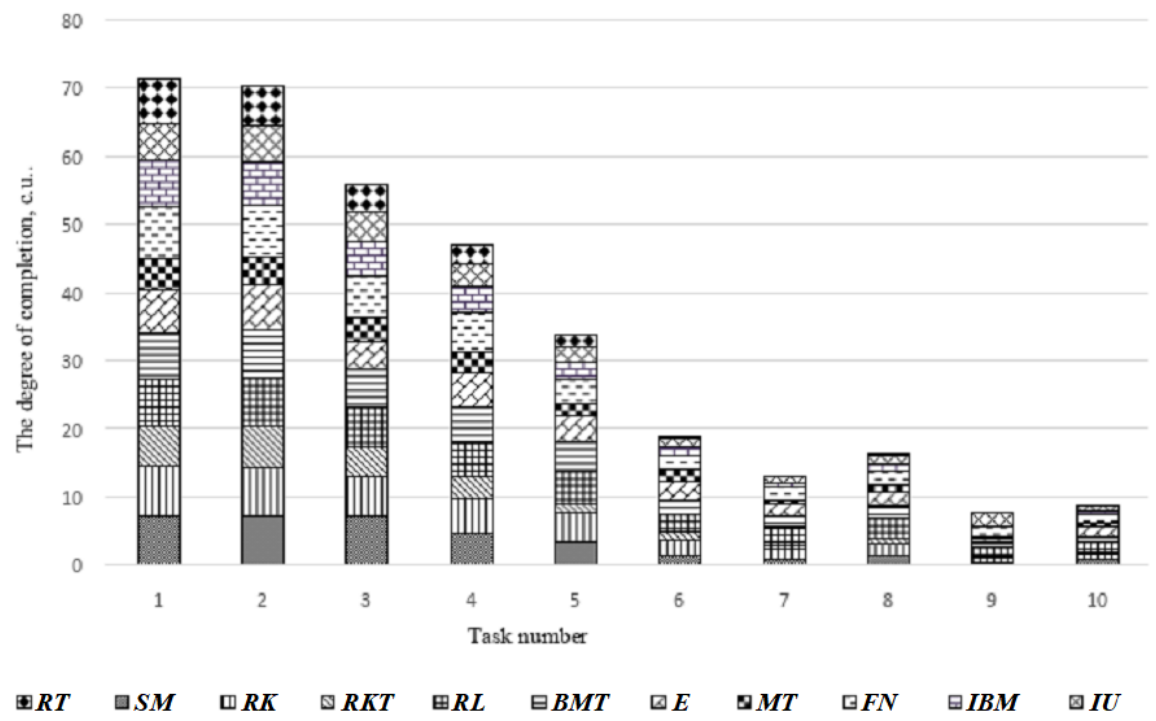

Fig. 2. The distribution of the average mark for each task for specific faculties in 2018 year.

The height of the column at Fig. 2 corresponds to the average mark for each task that students scored at a particular faculty. The diagram shows that the majority of students from all faculties solve mainly the first four tasks. The most actively solved tasks on the topic include kinematics and dynamics. In the same time the average score decreases extremely from the third to the tenth task. Namely, the solution of tasks from the fifth to the tenth, which consist of the foundations of molecular kinetic theory and thermodynamics, electrostatics, electric current, magnetic field and mechanical vibrations, is difficult. 
A graph on figure 3 shows the dependence of the average mark for a task on the task number for students of the SM department in 2018. The form of the graph is characteristic not only for students of SM department, but also for students of all departments and reflects, on the whole, the dynamics of decreasing the degree of solving tasks, starting with the third and fourth ones.

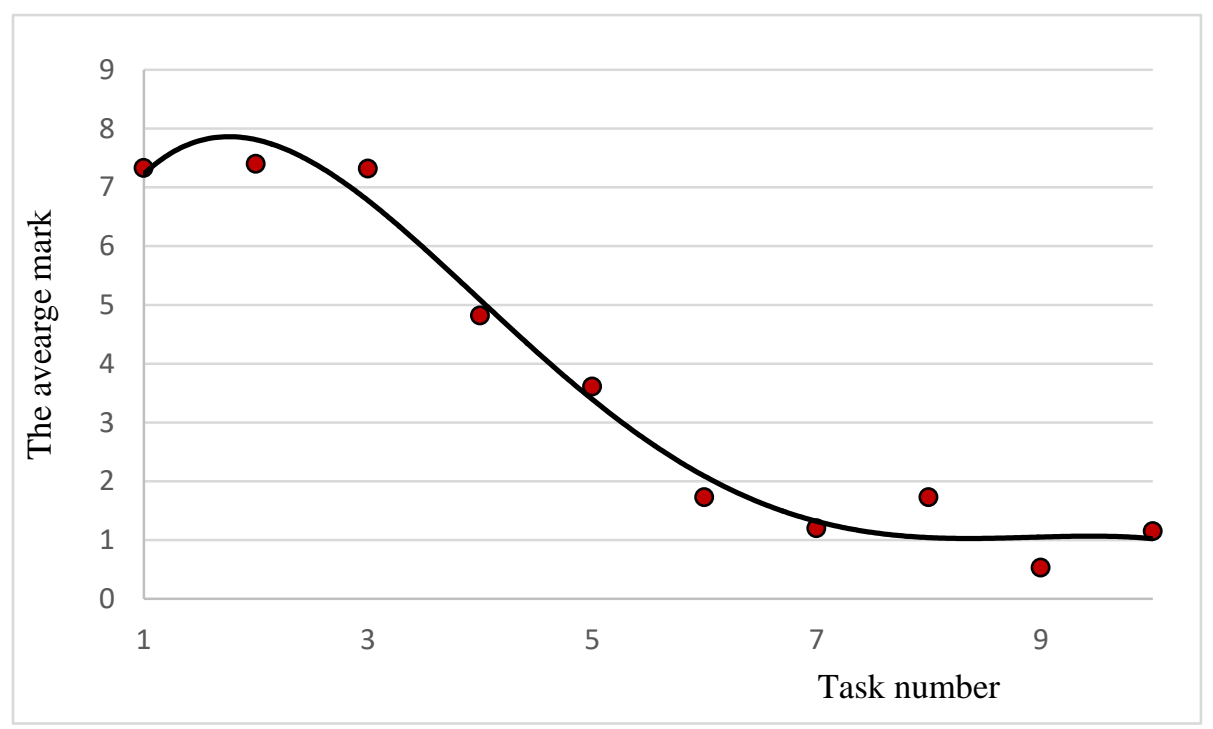

Fig. 3. Average mark at the SM department in 2018.

To justify the test results, a checkup of the points received by students for solving the problems of tests and passing marks at the university departments has been carried out. Figure 4 shows the passing marks in 2017, 2018, and 2019 years for faculties, students of which participated in entrance testing and whose results are presented in Fig. 2.

Further, two faculties - Fundamental Sciences (FN) and Mechanical Engineering (SM), which have a relatively stable passing marks, were selected for a more detailed analysis of the entrance testing results and their correspondence with the passing marks. Figure 5 shows the distribution of the results of the entrance diagnostic testing in physics for firstyear students at the Fundamental Sciences Department in 2019. The average marks for each task and for the department as a whole has been derived. For comparison, figure 2 shows similar indicators for students of the same department for this event, held in 2018. The average mark for the Department of Fundamental Sciences was 3.99 in 2018, and 3.01 - for 2019. The average mark for the Unified State Examination results for applicants at the Department of Fundamental Sciences was 224 in 2017, 245 - in 2018, and 251 - in 2019. The discrepancy in the results of physics entrance testing cannot be explained formally as insufficient training of students who entered the Department of Fundamental Sciences in 2018, as the average USE mark at the faculty is slightly higher in 2018 than in the previous year. 


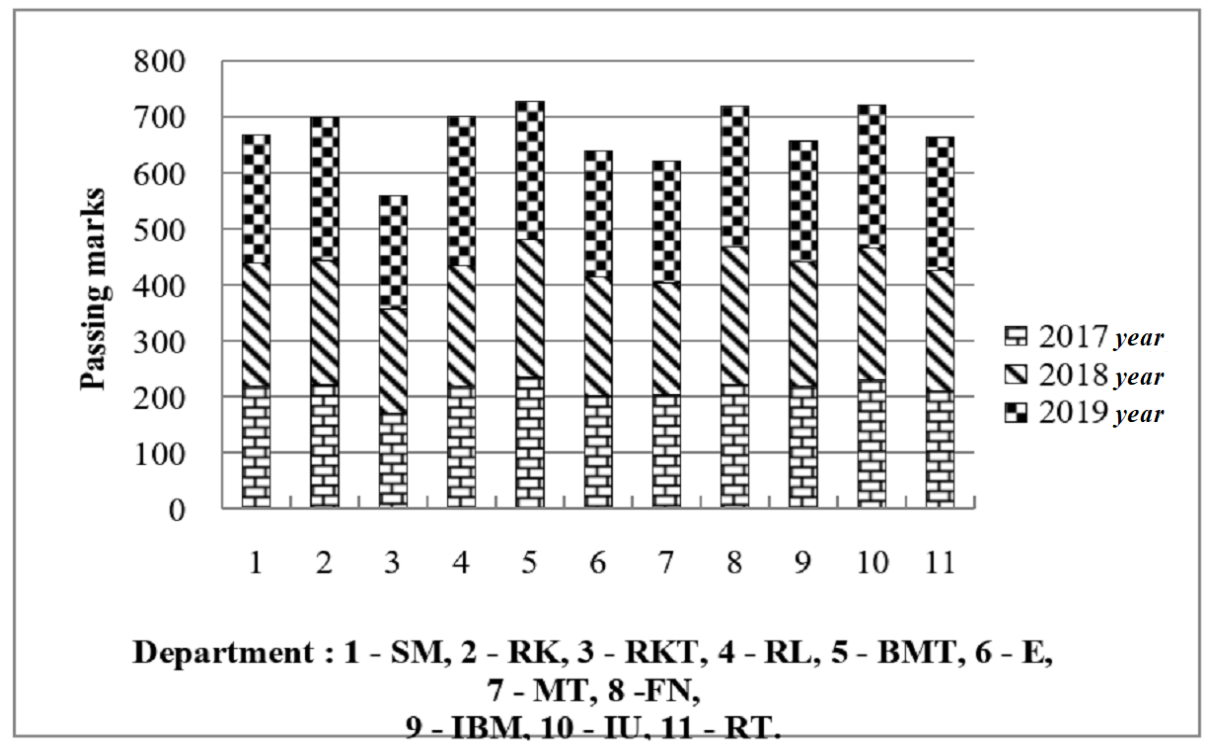

Fig. 4. Passing marks at BMSTU departments in the 2017, 2018, 2019 years.

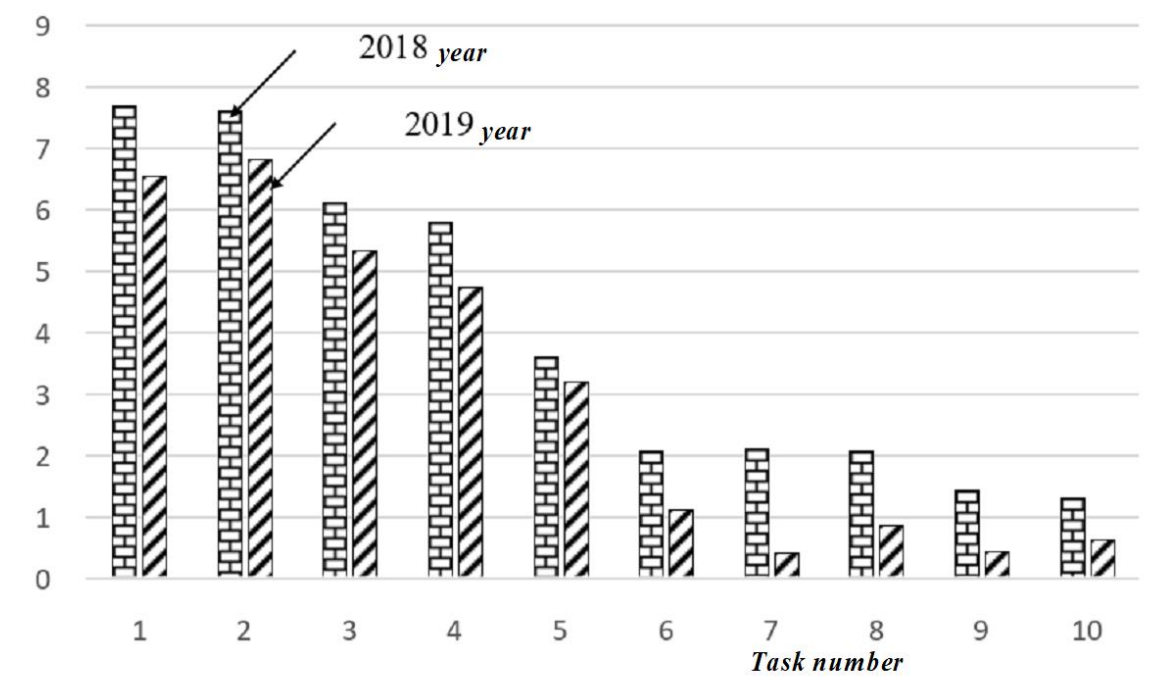

Fig. 5. Marks for the tasks of the entrance testing at the Department of Fundamental Sciences in 2018 and 2019.

The results of each test are brought to the attention of teachers conducting classes in the appropriate groups to take into account the provision of educational material on the subject during lectures, seminars and laboratory classes, as well as during the consultations.

Figure 6 shows the results distribution of the entrance diagnostic testing in physics for first-year students at the Department of Mechanical Engineering in 2019. The average mark for each task and for the department as a whole has been derived. For comparison, in figure 6 shows similar indicators for students of the same department for this event, which took place in 2018. The average mark for test tasks at the SM Department was 3.68 in 2018, and 3.51 in 2019. The average mark for the results of passing the exam for applicants at the 
Department of "Mechanical Engineering" and passing the physics entrance testing was 220 in 2017, 220 in 2018, and 230 in 2019. In this example, we also do not observe the correlation between the initial education of students when they were still applicants and the results of physics testing. The discrepancy in the results of the physics entrance test and their mismatch with the passing marks can be explained by insufficient residual knowledge of the subject, the lack of preliminary preparation by the time of the diagnostic work, which led to a decrease in the average marks obtained for test tasks. As in the case with the test results at the SM and FN Departments, it turns out that students have a decrease in the percentage of residual knowledge of the subject. It also affects the complexity of the subject, a large amount of theoretical material.

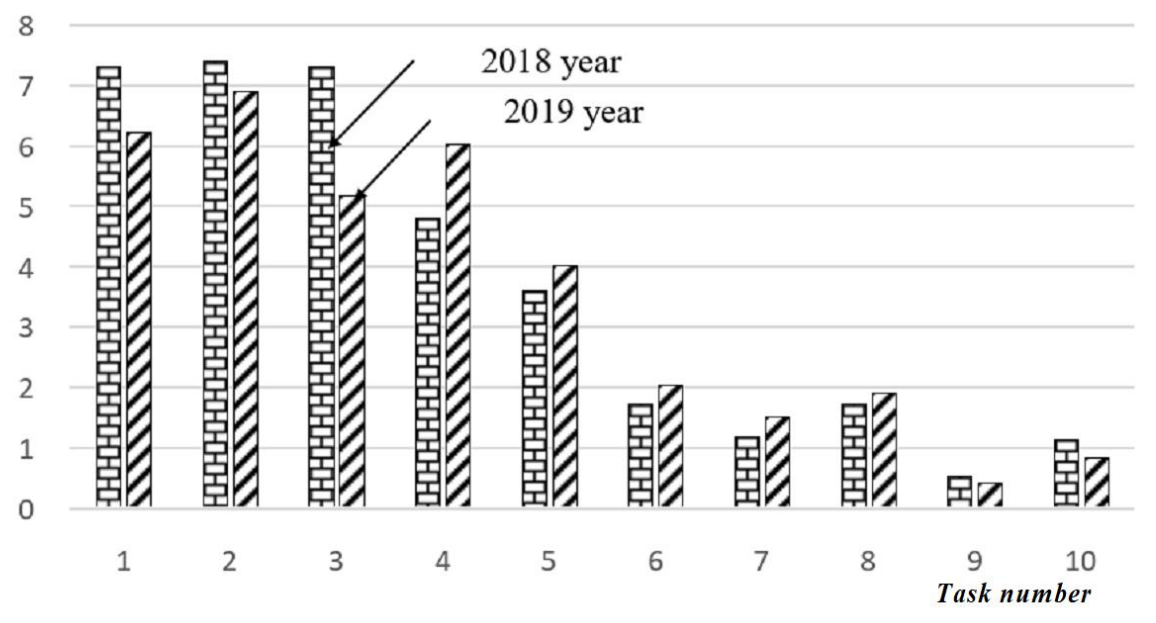

Fig. 6. Marks for the tasks of the entrance testing at the Department of Mechanical Engineering in 2018 and 2019.

\section{Discussion}

The analysis of the test results shows that only kinematics and dynamics (tasks №1 and №2) show positive results for the majority of students in the groups - 7.03 and 6.84 , respectively (6.50 and 6.41 in 2018) on a ten-point rating scale in 2019.

For other tasks, marks lower than passing grade were obtained ( $<6.00$ points). For all the tasks, the students of 2018 admission showed a slightly higher result than the students of 2017 admission.

For departments, the result was in the range of 2.49-4.38 (2.15-4.09 in 2018). The best overall mark is for the BMT department (4.38), RL department (3.98), E department (3.65), the worst is for the IBM department (2.49), RKT department (2.69), FN department (3.01).

The testing showed that students who entered in 2018 have a slightly higher preparation level than students who entered in 2017. Students of the RKT, E, BMT, MT, IU, RT departments have higher marks in relation to students of the previous year admission. The results of testing on the BMT (4.38, and a year earlier - 3.59), MT (3.08, and a year earlier 2.14), RT (3.36 and a year earlier - 2.15) departments were the best in comparison with the previous year ones. These indicators are lower for FN (3.0 and a year earlier - 3.99), RK (3.18 and a year earlier -3 .72), SM (3.5 and a year earlier - 3.68) departments.

The results of physics entrance testing prove that the topics "Electro-Statics", "Direct Current", "Magnetic Field" cause difficulties for students. The marks obtained for tasks 4 through 10 are minimal, in comparison with the marks received by students for tasks 1,2 . It 
can be seen from figures 1, 2, 3, 5, 6 that at all faculties the marks obtained for solving 9, 10 are almost 8-9 times less than for solving the first tasks. This result fits the concept, which was formulated in the 1970s. According to it a vast majority of university students have a low level of understanding in the sections "Electromagnetism", "Mechanical vibrations" [3]. A study on understanding the content of the general physics course sections by university students from different countries, including Russia, has been conducted to analyze the presence of this concept today. The research testing involved: Polytechnic University of Milan (Politecnico di Milano, ITA), Doshisha University (JAP), Bauman Moscow State Technical University. Pedagogical University - Università degli Studi di Trento (ITA) provided pedagogical support in the ongoing research. The tests from various tasks with an arbitrary choice have been developed for the experiment. About 750 students participated in tests. It was found that serious problems for students arise when studying the course "Electromagnetism", since the results tests on this topic were the lowest [17]. Due to the fact that there are many sections in the physics course that students know worst, the term "misconceptions" [3] was first introduced in 1972 in the context of studies aimed at primary school children. Studies have shown that difficulties arise not only during studying the "Electro-magnetism" course, but also during parts of the "Thermodynamics", "Mechanical vibrations and waves" and "Optics" courses [18].

First-year students, who study the basic physics course at the university, do not begin their studies in physics, but continue it. Therefore, the problems in the study are connected more likely with their own personal view and interpretive schemes of many physical phenomena [3,17].

The factors that make it difficult to obtain fundamental knowledge in physics can be divided by scientists into the following categories [17,19]:

- incorrect perception of physical phenomena, incorrect interpretation of experimental results;

- non-scientific beliefs that form a non-scientific worldview, for example, through the use of unverified sources of information;

- conceptual misunderstandings arising from the fact that students construct physical models without consulting with leading scientists or due to the lack of such scientists.

The problem of the future generation is that students begin to use incorrect physical models in practice, and that can lead to an emergency. As practice shows, retraining a person is more difficult than giving him fundamental knowledge in a timely manner, starting from school and ending with higher educational establishments. Some fundamental errors and false knowledge are stored in the human memory and in the future can be transmitted through generations $[3,17,18]$. In this regard, it is actual to create textbooks available for study on the theoretical and practical course of general physics [20-22]. The development of testing the assimilation of current knowledge and the diagnosis of entrance knowledge is a component of the university educational process.

The results of entrance testing cannot be completely objective, in the view of their comparison with the exam results, since students are not always serious about this type of diagnosis of their knowledge. The fact is that, formally, the marks obtained during the entrance diagnostic testing do not affect their further rating on the subject.

Summing up, we'll note that due to the development of information technologies, the process of improving the educational process cannot be limited in time and volume. However, despite the vast possibilities of education informatization, the level of education quality should not slow down. 


\section{Conclusion}

- During the educational process implementation in a higher educational institution, it is necessary to control the gained knowledge, which allows to adjust the further process of student's education.

- Testing is an actual form of quality control of students' education in the subject and it is relevant to assess the amount of learned discipline. In this case, the initial control level of the student's fundamental base is important. Since entrance testing is carried out for all students, that is, for all faculties whose students undergo a course of general physics under the curriculum, this allows to assess the quality and level of learning physics for full-time students of the first course of BMSTU. The results of a statistical analysis on the exam results conformity may be taken into account when creating educational activities in the "General Physics" discipline. At the same time, it should be borne in mind that students may befall to entrance testing without understanding its' significance and therefore the results of the entrance testing cannot reflect the real situation. Therefore, this type of control of the comprehensibility of the academic discipline content should be included in the admission criterion to the discipline or the results of the entrance knowledge control should be integrated with a point-rating system.

- Test results indicate the need to develop alternative methods for diagnosing the level of preparedness of first-year students of a technical university, and also provide information for the formation of differential groups of students based on their education level.

\section{References}

1. O.S. Erkovih, N.A. Zadorozhnyi, A.N. Morozov, M.L. Pozdyshev, S.L. Timchenko, "Russian teaching method" at the Department of Physics in the preparation of engineers, Physical education in universities 22 (4), pp. 5-19 (2016)

2. N.A. Zadorozhnyi, A.N. Morozov, S.L. Timchenko, Physical education in high schools, State and prospects of a physical workshop at a technical university 22 (3), pp. 46-54 (2016)

3. R.L. Doran, Misconceptions of Selected Science Concepts, Journal of Research in Science Teaching, Vol. 9, pp. 127-137 (1972)

4. A.L. Odom, L.H. Barrow, Development and application of a two-tier diagnostic test measuring college biology students' understanding of diffusion and osmosis after a course of instruction, Journal of Research in Science Teaching, Vol. 32, pp. 45-61 (1995)

5. D.C. Washington, National Academies Press. Committee on Undergraduate Science Education, "Misconceptions as Barriers to Understanding Science" in Science Teaching Reconsidered A Handbook, pp. 27-32 (1997)

6. M. Zani, M. Bozzi, La fisica tra la scuola secondaria e l'università. Riflessioni e orientamenti, Nuova Secondaria, Vol. XXXVI. 1, pp. 84-88 (2018)

7. A. Elby, Helping physics students learn how to learn, American Journal of Physics 69(S1), pp. 54-S64 (2001)

8. O.S. Erkovich, S.P. Erkovich, A.N. Morozov, A.A. Esakov, I.S. Golyak, Physical education in high schools, The matrix method of forming the program of the subject "Physics", 18 (3), pp. 32-37 (2012) 
9. A.V. Popov, Testing as a method of controlling the quality of students' knowledge, Proceedings of the St. Petersburg State University of Culture and Arts, 200, pp. 283286 (2013)

10. O.V. Gabova, A.A. Rusakov, Pedagogical informatics, Testing is one of the forms of diagnosis and verification of the success of education 3, pp. 13-17 (2005)

11. T.Yu. Tsibizova, V.M. Postnikov, S.B. Spiridonov, Analysis of the influence of lecturevisualization technologies on the results of control measures in academic disciplines, Prospects for Science and Education, 3 (33), pp. 358-363 (2018)

12. I.K. Andronchev, D.S. Dmitriev, N.V. Solovova, Bulletin of Samara State University, Management of the educational process of a university by means of information and communication technologies 1, pp. 171-176 (2014)

13. I.K. Andronchev, N.V. Solovova, S.A. Ivanushkina, D.S. Dmitriev, Bulletin of Samara State University, Comparative and correlation analysis of input testing in mathematics and physics at Samara State University, 2 (124), pp. 9-20 (2015)

14. P.J. Feltovich, R.J. Spiro, R L. Coulson, Learning Teaching, and Testing for Complex Conceptual Understanding, Test theory for a new generation of tests, pp. 193-230, Routledge (2012)

15. M. Hill, M. D. Sharma, H. Johnston, European Journal of Physics, How online learning modules can improve the representational fluency and conceptual understanding of university physics students, 36(4), 045019 (2015)

16. M. Kim, J. Choi, J. Song, Developing a web-based system for testing students' physics misconceptions (WEBSYSTEM) and its implementation, Journal of the Korean Association for Research in Science Education, 27(2), pp. 105-119 (2007)

17. M. Bozzi, P. Ghislandi, K. Tsukagoshi, M. Matsukawa, M. Wada, N. Nagaoka, A. B. Pnev, A. A. Zhirnov, G. Guillerme, M. Zani, Highlight misconceptions in physics: A T.I.M.E. Project, Proceedings of INTED2019 Conference 11th-13th March 2019, Valencia, Spain, pp. 2520-2525 (2019)

18. P. Colin, F. Chauvet, L. Viennot, Reading images in optics: students' difficulties and teachers' views, International Journal of Science Education, 24(3), pp. 313-332 (2002)

19. T. Martín-Blas, L. Seidel, A. Serrano-Fernández, Enhancing Force Concept Inventory diagnostics to identify dominant misconceptions in first-year engineering physics, European Journal of Engineering Education, 35(6), pp. 597-606 (2010)

20. J. Raffaghelli, P. Ghislandi, S. Sancassani, L. Canal, R. Micciolo, B. Balossi, M. Bozzi, Laura Di Sieno, I. Genco, P. Gondoni, A. Pini, M. Zani, Integrating MOOCs in physics preliminary undergraduate education: beyond large size lectures, Educational Media International, 55 (4), pp. 301-316 (2018)

21. J. Park, S. Han, Using deductive reasoning to promote change of students' conceptions about force and motion, International Journal of Science Education, 24 (6), pp. 593 609 (2010)

22. M. Bozzi, J. Raffaghelli, M. Zani, Peer learning for large size Physics lectures in higher education: yes, we can, Proceedings of iCERi2018, pp. 8739-8747, Seville, Spain: IATED (2018) 